\title{
Design e identidade nos quadrinhos de Grande Sertão
}

\section{Crossing: design and identity in the graphic novel Grande Sertão}

COUTO, Daniela Martins Barbosa; mestre em Letras pela UFSJ e doutoranda em Design: linha de pesquisa "Cultura, Gestão e Processos em Design"; UEMG.

danielambc@gmail.com

RIBEIRO, Rita Aparecida da Conceição; orientadora e docente no Programa de Pós-Graduação em Design da Escola de Design da UEMG.

rribeiroed@gmail.com

\section{Resumo}

O design, percebido enquanto uma linguagem conforme Sudjic (2010), concedeu uma forma singular ao romance Grande Sertão: veredas ao adaptá-lo para graphic novel. Ao transportar o sertão roseano para outro formato, a obra constrói outra identidade para o romance e para a narrativa e é a interação entre esses aspectos e o design, o foco da discussão aqui realizada. 0 recorte se faz por meio de observações sobre o design gráfico e tem como referências Bonsiepe (2016) e Moraes et.al (2016), para a discussão sobre design e identidade; Ribeiro (2003), em relação à comunicação visual e composição gráfica, e Benjamin (1987) no que se refere à narrativa. O objeto de estudo é composto por quadrinhos da graphic novel Grande Sertão: veredas - adaptação da obra de João Guimarães Rosa (2014). Ao final do estudo, observou-se que a identidade do sertão foi ressignificada pela construção de uma atmosfera que integrou a escrita roseana aos traços de personagens, cores, tons e curvas de rios e montanhas.

Palavras-chave: Design, narrativa visual, graphic novel.

\section{Abstract}

The design, perceived as a language according to Sudjic (2010), granted a singular form to the novel Grande Sertão: veredas when adapting it for graphic novel. When transporting the rosean sertao to another format, the work constructs another identity for the novel and for the narrative and is the interaction between these aspects and the design, the focus of the discussion carried out here. The cut is made through observations about graphic design and has as references Bonsiepe (2016) and Moraes et.al (2016), for the discussion on design and identity; Ribeiro (2003), in relation to visual communication and graphic composition, and Benjamin (1987) regarding the narrative. The object of study is composed by graphic novels Grande Sertão: veredas - adaptation of the work of João Guimarães Rosa (2014). At the end of the study, it was observed that the identity of the sertão was re-signified by the construction of an atmosphere that integrated roseana writing with the character traits, colors, shades and curves of rivers and mountains.

Keywords: Keywords: Design, visual narrative, graphic novel. 


\section{Introdução}

A voz do avô foi o primeiro livro, a primeira narrativa - oral, diga-se de passagem. "Era um contador de histórias nato", respondeu Hautom (2008, p.1). Nesse detalhe, há de se lembrar do narrador clássico conceituado por Benjamim (1987): aquele que tece suas histórias da vivência e retira dela as experiências que se tornam sabedoria tecida através do contar e recontar. $E$ aqui os termos não são aleatórios: "através", pois perpassa a própria vida; "tecida", pois existe o emaranhado de linhas e entrelinhas, e há, ainda, o labor posto que tecer, sejam as palavras escritas, sejam as palavras faladas, e, ainda, as imagens, envolve o trabalho contínuo da memória.

Esse trabalho, responsável também pela formação da identidade, é, pois, construído como colcha de retalhos ou, no caso aqui observado, por quadrinhos que ressignificam o romance Grande Sertão: veredas. O design adotado na adaptação da obra para graphic novel, que resultou na edição especial limitada a sete mil exemplares, com 180 páginas de miolo no formato $21 \mathrm{~cm} \times 28 \mathrm{~cm}$ e impressão em offset $180 \mathrm{~g} / \mathrm{m}^{2}$, realçou contextos sociais, culturais e ambientais da narrativa, contribuindo também para a construção de outras memórias sobre o sertão, pois:

É justamente porque não estamos mais inseridos em uma tradição de memória viva, oral, comunitária e coletiva, como dizia Maurice Halbwachs, e temos o sentimento tão forte da caducidade das existências e das obras humanas, que precisamos inventar estratégi as de conservação e mecanismos de lembrança (GAGNEBIN, 2006, p. 97).

O design da página impressa pode ser percebido como um dessas estratégias de conservação da memória e o material que dele resulta, como o mecanismo de recordação. 0 formato do livro, o suporte de impressão, o uso da cor, os traços das ilustrações, a ordenação das cenas, a interação entre palavra e imagem, enfim, todos esses elementos constroem sentidos para o produto e identificam contextos do romance aos quais são acrescidos novas informações visuais, e, assim, ressignificam a obra e evocam o sertão por meio de novos traçados.

E, ao observar esse sertão roseano sob o prisma do design, é possível encontrar muitos afluentes. No Brasil, o design ainda está em travessia e, assim, sua cultura e história seguem rumo à consolidação. É, pois, como "um rio: um rio também tem tempo para virar rio... é um rio em formação, até um dia, se tornar o rio definitivo" ${ }^{1}$. Nesse percurso, ele tem a possibilidade de encontrar diversos cursos d'água que irão, aos poucos, agregar correntezas novas ao seu leito; passar por caminhos diversos que tendem a integrar perspectivas diferentes aos conceitos já discutidos e encontrar problemas que põem em pauta questões até então não observadas.

Também é como um rio em construção, a identidade que o design constrói por meio dos projetos e produtos que elabora e, para refletir sobre isso, este estudo tem como objeto o livro Grande Sertão: veredas - adaptação da obra de João Guimarães Rosa (2014), sendo o recorte composto por três quadrinhos da graphic novel. A proposta é, pois, perceber algumas das travessias de interpretação proporcionadas pelas confluências entre identidade e design, e, com

\footnotetext{
10 trecho fez parte da exposição oral do professor Dijon de Mora es, durante a a ula de Teorias e Cultura do Design/Conceitos e m Design ministrada no dia 29 de novembro de 2017 no curso de doutorado em Design, da UEMG, na sede da instituição, e $m$ Belo Horizonte (MG).
} 
isso, identificar o significado de sertão que surge dessa interação. Para isso, será discutido no próximo tópico, questões sobre design, identidade, comunicação visual e produção simbólica, tendo como elementos de análise, os quadrinhos que compõem este estudo.

\section{Design e identidade cultural}

Muitas são as interpretações sobre o romance Grande Sertão: veredas, de João Guimarães e vasta é a produção crítica a respeito. No entanto, no campo do design, a obra roseana encontra um amplo campo para reflexão, ainda mais considerando-se as leituras visuais e gráficas elaboradas nos últimos tempos. Para Bolle (2006), a obra de Rosa (2006) pode ser lida como um romance de formação da alma de um indivíduo e, ainda, como retrato de um país, pois traz para a narrativa aspectos ambientais, sociais e culturais que constroem imagens sobre o território, em especial, o interior do Brasil.

Ainda hoje, quando se fala de sertão, a memória discursiva traz a imagem de um lugar ermo e distante, seco e sem muitos recursos. Mas, conforme Bolle (2004), o sertão do romance de Guimarães Rosa é "movimentante" todo o tempo, estabelece uma relação com a linguag em e se constrói, ainda, como lugar de memória e mapa de uma história social: "as dezenas de veredas desse mapa topográfico traçado a partir da rememoração de Diadorim desdobram-se em centenas de retratos de sertanejos e jagunços que Riobaldo (Guimarães Rosa) conheceu e criou" (BOLLE, 2004, p. 225).

O sertão, ainda que seja o espaço lá do interior, é também o tempo e as condições pelas quais o discurso sobre ele é tecido. Essa rede, composta de dispersões que envolvem diferentes enunciados que convivem entre si, conduz a um processo de enunciação que não se repete, pois os tempos - e, ainda, os espaços e as circunstâncias - não são os mesmos.

De acordo com Foucault (1999), a memória discursiva é tudo aquilo que foi ouvido durante toda a vida e que se atualiza conforme quem fala e de onde fala. Percebe-se, ainda, a formação discursiva, que é esse feixe de relações e interações que formam e envolvem os enunciados, abrangendo o que já foi dito e, ainda, o que pode e o que não pode ser dito a respeito de alguma coisa. Nessa discussão, ainda cabe lembrar o interdiscurso, ou seja, aquilo que está presente no discurso e o relaciona a diversos outros discursos. Segundo Foucault (1999), o interdiscurso e a formação discursiva são constitutivos, ou seja, não podem ser separados, pois um só existe porque o outro existe.

A memória e a formação discursiva se fazem presentes nos traços que ilustram o livro. Sendo assim e a partir da adaptação do romance para graphic novel, torna-se possível pensar a obra também pela vertente do design, uma vez que ele, conforme Sudjic (2010, p. 21), "passou a ser a linguagem com que se molda objetos e confecciona as mensagens que eles carregam" e, por isso, os designers têm, hoje, o papel de "tanto de ser contadores de histórias, fazer um design que fale de uma forma que transmita essas mensagens, quanto resolver problemas formais e funcionais" (SUDJIC, 2010, p. 21). E esse design que promove a transmissão clara de mensagens pode ser observado na obra roseana adaptada para quadrinhos. 
No livro, percebido enquanto produto cultural, a linguagem utilizada concede visualidade à história de Riobaldo e possibilita uma sequência linear para o enredo, ainda que mantenha trechos com a escrita original do livro. As "andanças" dos personagens pelo sertão tornam-se mais claras e os lugares e os tempos são identificados por meio de traços e cores bem definidos. 0 romance torna-se, pois, mais acessível, porém, não menos complexo, uma vez que a interação entre ilustração e texto constrói a imagem do sertão por meio do interdiscurso e das referências cotidianas à paisagem brasileira, em especial, à mineira, conforme pode ser observado na FIG. 1 Riobaldo e sua fazenda.

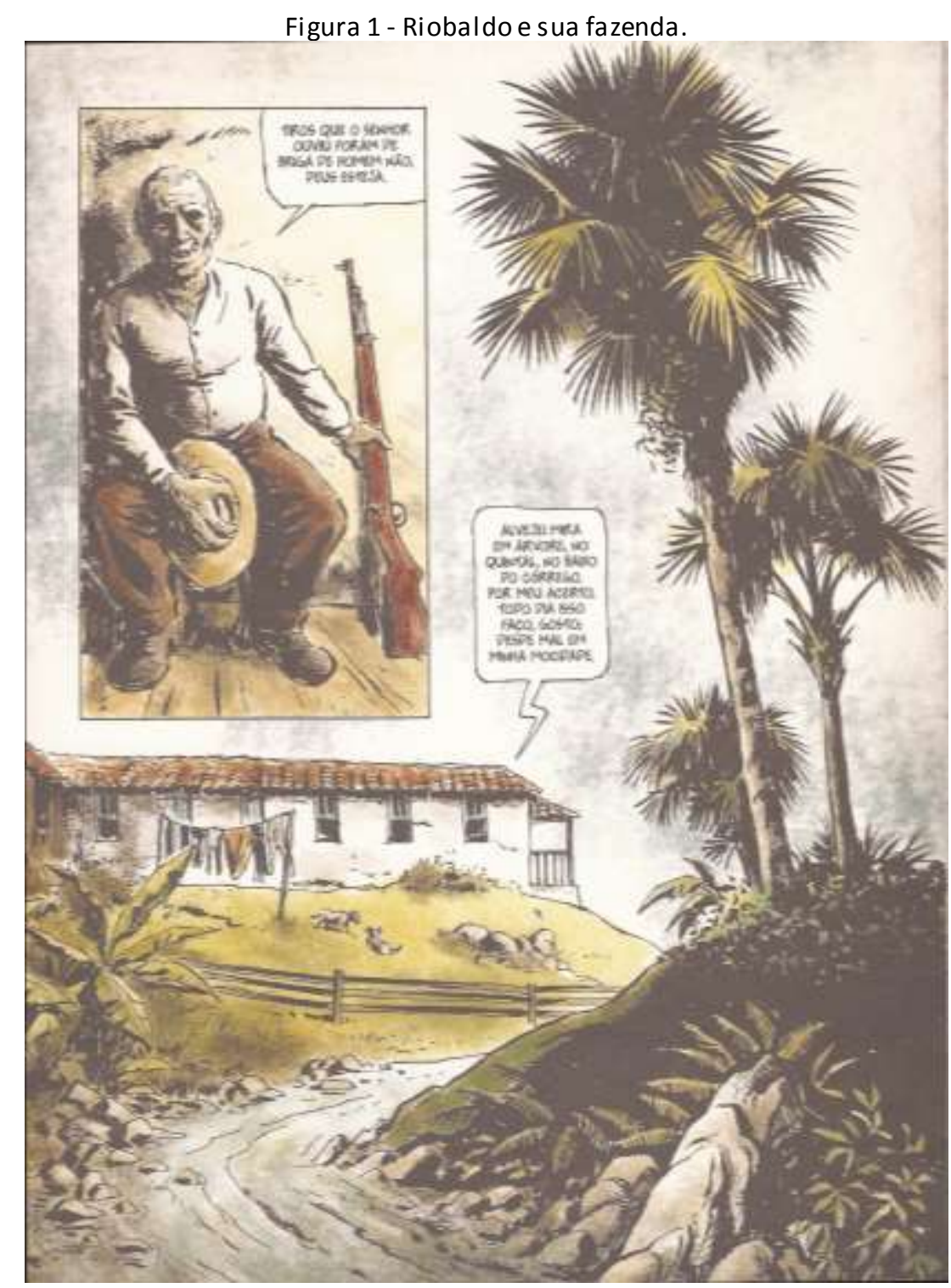

Fonte: ROSA e GUAZZELLI, 2014, p.10.

A formação discursiva sobre o interior é, pois, representada pela composição visual. Ribeiro (2003) avalia que ela é uma tomada de decisão na qual ilustrações, textos e suas respectivas posições na página constituem enunciados autônomos, mas que, em conjunto, elaboram o design da página, emitem mensagens, constroem significados e produzem a leitura. Assim, o discurso visual conduz o olhar pela página e concede a primeira percepção sobre o 
conteúdo. No caso da FIG. 1, a fala do personagem - "tiros que o senhor ouviu foram de briga de homem não, Deus esteja" - junto ao gesto de segurar o chapéu com uma das mãos, remete a uma marca cultural do interior do país, marcada pelos rituais religiosos, que é retirar o chapéu quando se pronuncia o nome de Deus.

Na mesma página, os traços da casa de Riobaldo remetem à arquitetura colonial e a paisagem, aos rios, morros e buritis que povoam a paisagem do interior do estado de Minas Gerais, região onde o personagem viveu, conforme o romance roseano. Outro detalhe observado se refere à ilustração dos varais onde as roupas são colocadas para secar, atitude comum no interior do estado e que diz respeito à memória cultural do brasileiro. A inserção das falas dos personagens conforme a grafia original de Guimarães Rosa, que reproduz, na palavra escrita, a fala coloquial, também faz com que esse contexto se aproxime mais do cotidiano.

A adaptação da obra para graphic novel, em certa medida, altera o modo como a obra original de Rosa é lida e percebida. Enquanto que para Bolle (2006), o livro de Guimarães Rosa é um retrato do Brasil aberto a significações relacionadas ao contexto sociopolítico do país no final do século XIX e início do século XX, e que, portanto, pode construir imagens diferentes na mente do leitor, conforme suas referências, a adaptação da obra para quadrinhos faz com que essas imagens ganhem formas definidas e explicativas. Os sentidos, portanto, são mais restritos, sendo produzidos na articulação dos elementos visuais pres entes na relação imagem/texto.

Diante disso, pode-se dizer, conforme Sudjic (2010, p. 51), que "o design é usado para moldar percepções de como os objetos devem ser compreendidos [...] é uma linguagem que evolui e modifica seus significados tão depressa como qualquer outra [...] Mas é a chave para entender o mundo feito pelo homem" (SUDJIC, 2010, p.15) e, no caso aqui observado, o mundo construído na obra Grande Sertão: veredas. O sertão é, pois, constituído pelos traços - tanto da grafia, quanto do desenho - do interior: o pensamento sobre ele ganha formas e tece uma discussão sobre questões históricas como coronelismo, política e jagunçagem, além de aspectos que integram memórias do personagem-narrador Riobaldo às características ambientais, arquitetônicas e culturais do país, e, com isso, contribuem com a formação da identidade de uma coletividade.

O que sobra para um designer lidar é a superfície, a a parência e as nuances semânticas do significado que nos permitem interpretar e entender o que um objeto está tentando nos dizer sobre si mesmo [...] São questões que estãolonge de ser triviais, mas transformam o designer em narrador. E, embora sem dúvida seja verdade que o design é uma linguagem, só quem tem uma história convincente para contar sabe usar essa linguagem de maneira fluente e eficaz (SUDJIC, 2010, p. 34).

E a linguagem flui, assim como o Urucuia, o "de Janeiro" e o "do-Chico", rios que desenham os caminhos da história de Riobaldo: "Saí, vim, destes meus Gerais; voltei com Diadorim. Não voltei? Travessias... Diadorim, os rios verdes [...] O meu Urucuia vem, claro, entre escuros. Vem cair no São Francisco, rio capital. O São Francisco partiu minha vida em duas partes. (ROSA, 2006, p. 309-310). A história, agora, é construída pelas palavras, mas também, pelos silêncios e pelas ilustrações, e, em ambos os casos, o labor é manual, ainda que os traços de um deem formas à escrita, e os traços do outro, às imagens. Por ser um labor manual, juntos, tornam- 
se também narrativas, daquelas discutidas por Benjamin (1987) e que são tecidas por meio da vivência e costuradas por meio da experiência, sendo contadas e recontadas pelo tempo afora, pois não se entregam à explicação, mas, pelo contrário, conservam em si a capacidade de se reproduzirem em outras muitas leituras.

Nesse contexto, pode-se observar que o design, enquanto meio para produção de significados, é também narrativa, pois a relação dele com os objetos que cria é, também, uma relação artesanal, assim como é a do narrador com a vida humana. A interrogação de Benjamin (1987, p. 221) - "Não seria sua tarefa trabalhar a matéria-prima da experiência, a sua e a dos outros, transformando-a num produto sólido, útil e único?" -, pode, então, ser respondida aqui: sim, é tarefa tanto do narrador quanto do designer trabalhar essa matéria-prima e transformá-la em produtos singulares. A partir desse trabalho, que também têm ressonâncias na memória cultural, os elementos identificatórios são elaborados, considerando os contextos para os quais as produções se destinam, e podem se tornar únicos na medida em que representam determinadas características socioculturais e ambientais desse espaço/tempo. Na FIG. 2, essa narrativa pode ser observada, bem como a memória cultural que permeia os traços que dão formas e tom à cena.

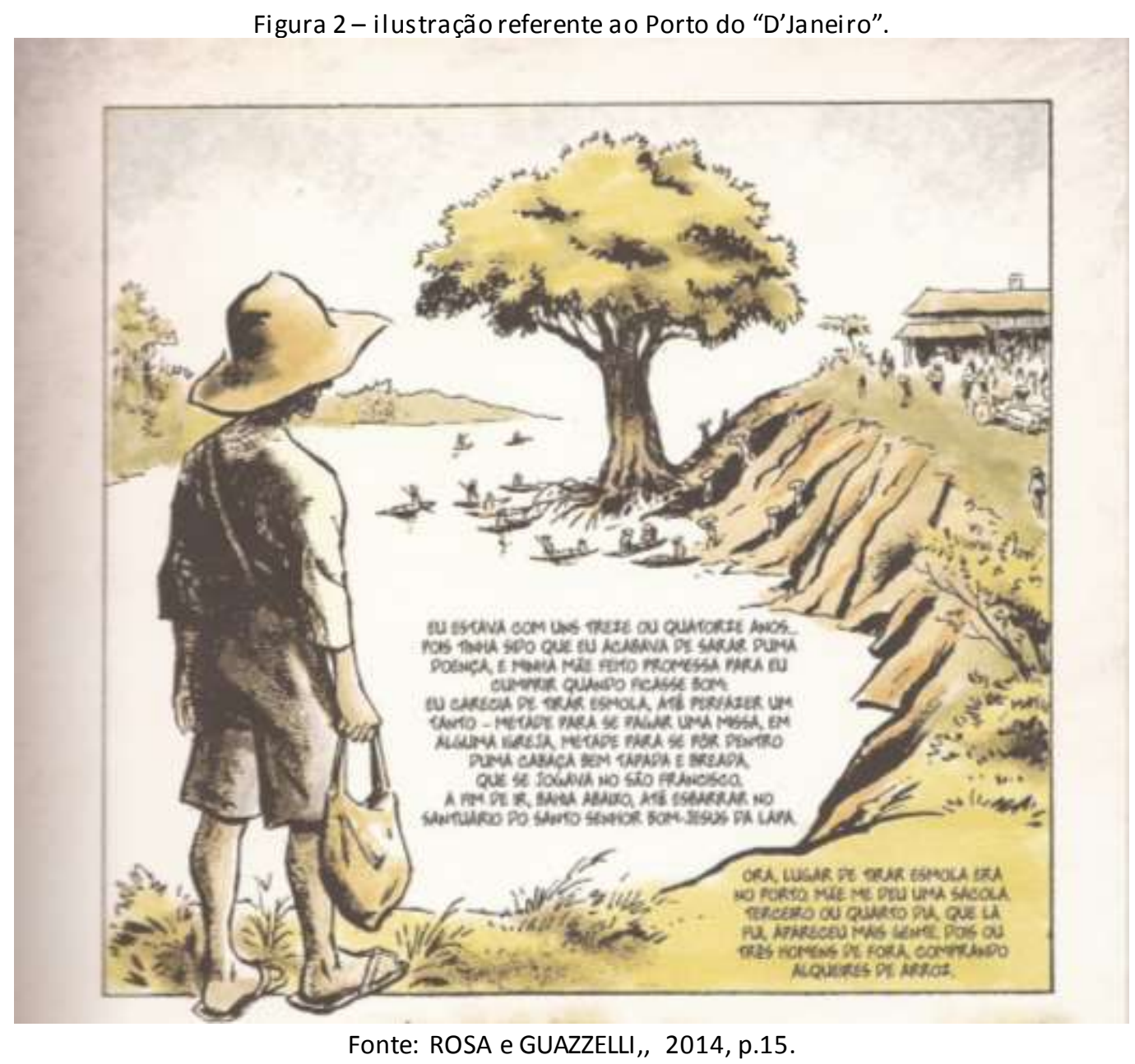

Do alto de um barranco, o menino observa o porto que é entendido enquanto tal devido ao texto que o acompanha: por isso, ele torna-se único, pois ali é o 'd'Janeiro', afluente do São 
Francisco e, portanto, travessia que, em Grande Sertão: veredas, marca o primeiro encontro entre Riobaldo e Diadorim. A religiosidade, traço cultural relacionado com o interior, também se faz presente na cena, por meio da referência ao pagamento de promessa:

Eu carecia de tirar esmola, até perfazer um tanto - metade para se pagar uma missa, em alguma igreja, metade para se pôr dentro de uma cabaça bem tapada e breada, que se jogava no São Francisco, a fim de ir, Bahia abaixo, até esbarrar no Santuário do Santo Senhor Bom Jesus da Lapa (ROSA, 2014, p. 15).

Detalhe também para o chapéu, acessório que, na graphic novel, caracteriza o personagem e o acompanha desde o primeiro quadro. Só que, aqui, o chapéu está posto, pois o nome sagrado não é invocado, mas, sim, citado em referência a um lugar específico. No interior mineiro, principalmente em localidades mais marcadas pela tradição rural, o uso do chapéu é algo comum e cotidiano, e integra o modo de vida da população. O menino, Riobaldo, traz consigo também uma capanga, utensílio simples e feito à mão que, em tempos mais antigos, era bastante utilizado pelos tropeiros durante suas viagens. Já o calçado - uma sandália de tiras - representa ali a humildade e a simplicidade do menino que vai ao porto pedir esmolas para pagar uma promessa feita por sua mãe. Em conjunto, todos esses elementos criam um contexto que identifica o personagem tanto por meio de suas crenças, quanto pela sua situação social.

Em se tratando de identidade, Moraes, Krucken e Reyes (2016, p. 9) observam que falar dela "é lidar com a complexidade [...] Falar de identidade pode denotar semelhança - sentido de pertença a um grupo ou nacionalidade, por exemplo - e, simultaneamente, nos traz a ideia de singularidade - algo único, original, autêntico". É, pois, no encontro de elementos repetidos e, ao mesmo tempo, diferentes que as características de dado contexto, grupo, cultura ou lugar se constituem como um conjunto de significados que, ao longo do tempo, criam o sentimento de pertencimento. "Podemos, portanto, dizer que a memória é um elemento constituinte do sentimento de identidade, tanto individual como coletiva" (POLLACK, 1992, p. 2). E, na obra observada, o sertão é esse lugar em que a memória individual e coletiva se encontram para dar forma ao romance por meio dos quadrinhos.

O indivíduo - seja ele Riobaldo, Diadorim ou quaisquer outros personagens que povoam o romance -, é, pois, parte de uma coletividade, de um espaço e de um tempo maior, e conforme já observava Pollack (1992), se constitui também na alteridade. Diadorim são os "rios verdes", conforme palavras de Riobaldo, mas também é o menino valente que, ao ser questionado sobre o medo, responde que "é preciso ter coragem". Cada uma dessas identificações se fundamentam, pois, em consonância com a memória e em relação aos demais momentos e personagens da obra.

A construção da identidade é um fenômeno que se produz em referência aos outros, em referência a os critérios de aceitabilidade, de admissibilidade, de credibilidade, e que se faz por meio da negociação direta com outros. Vale dizer que memória e identidade podem perfeitamente ser negociadas, e não são fenômenos que devam ser compreendidos como essências de uma pessoa ou de um grupo (POLLACK, 1992, p. 5).

A memória e a identidade, construídas por meio da interação entre passado e presente, entre o singular e o universal, são, também, questões que puderam ser observadas na figura analisada, cujo contexto cultural remete ao interior de Minas Gerais que, ainda hoje, mantém 
muitas tradições, tanto relacionadas ao comportamento, como o pagamento de promessas, quanto aos hábitos, entre eles, o uso do chapéu. São, portanto, elementos identificatórios de uma determinada população que, ao ganhar os contornos da imagem ilustrada, fazem com que o singular se torne, também, universal, pois seus significados passam a ser compreendidos pelos povos mais distantes, assim como o rio e suas margens (FIG. 3).

Figura 3 - Rio São Francisco.

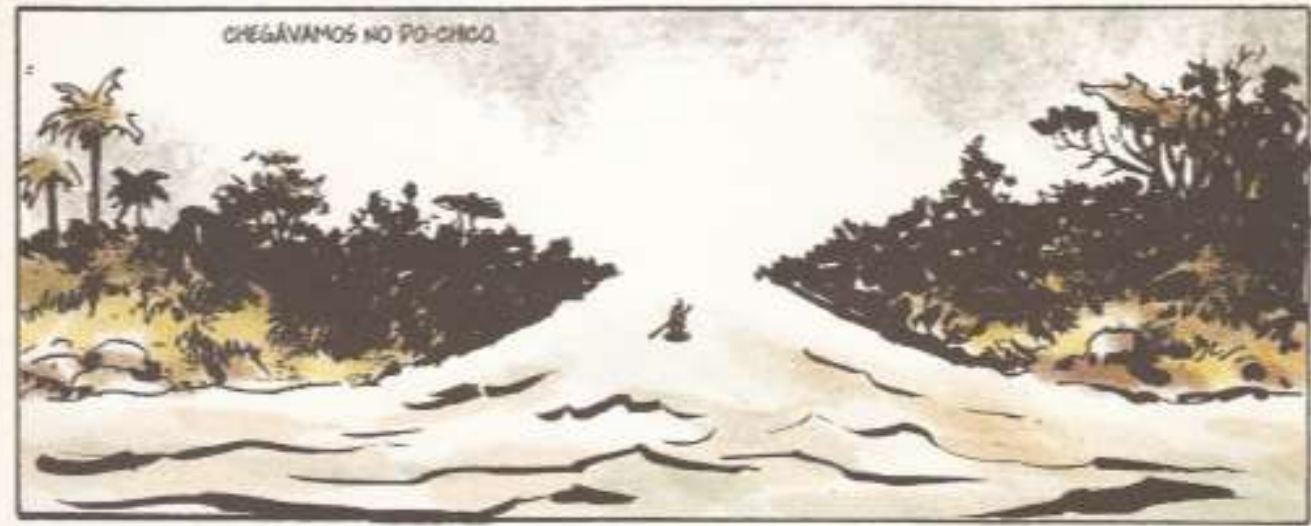

Fonte: ROSA e GUAZZELLI, 2014, p.18

A legenda, no alto do quadro, informa: "chegávamos no do-chico". Ao centro da imagem, a silhueta de alguém em um barco a remo, no meio do rio, no centro da travessia; em cada uma das margens, contornos que lembram os olhos; ao lado esquerdo, os buritis, característicos da paisagem do sertão mineiro; ao lado direito, a vegetação predominantemente baixa, representativa da mata de cerrado; no quadrante superior, de uma a outra margem do quadro, o céu e, no inferior, da mesma forma, o rio; e, na ligação entre eles, pode-se perceber o símbolo estilizado do infinito, marca que na obra original de Rosa (2006) encerra o romance, sendo colocado logo após a última frase e que, na graphic novel, está na abertura e no encerramento da obra. São dois lugares tão distintos, assim como o céu e o rio, mas que se encontram em um ponto comum: a travessia do Grande Sertão: veredas e a criação da identidade sobre esse lugar, ao mesmo tempo tão ficcional e real, construído por meio da linguagem.

A pesquisa literária mostra que identidades são em primeirolugar construtos cria dos pel a linguagem, porém, não menos mediante recursos visuais [...] A identidade não é tanto o que cada um tem, mas sim vive no imaginário do outro. Identidades pertecem ao l'imaginaire. Elas são artefatos de comunicação (BONSIEPE, 2016, p. 67).

Dessa maneira, os traços do sertão fluem de leve, ora sinuosos, ora angulares e dão forma aos buritis, às montanhas, às curvas dos rios. Aliás, há que se lembrar o quão parecidos são os rios e as identidades: ambos se fazem no ir e vir das travessias ao longo do tempo. Na superfície, os traços que caracterizam cada coisa e, no design, os que dão forma aos objetos. Bonsiepe (2016, p. 64), por sua vez, observa que "a pergunta pela identidade nas disciplinas projetuais surgiu, sobretudo, na comunicação visual, no design industrial, no artesanato e até na arquitetura, porque, por um lado, as disciplinas conceituais formam práticas da vida cotidiana e, por outro, refletem diferentes práticas culturais da vida cotidiana". Daí, o encontro entre o design e a 
narrativa, pois ambos tratam do cotidiano, das vivências que nele acontecem, das práticas ali realizadas, dia após dia, contam a história e constroem a identidade de um lugar, de um povo, de um tempo...

\section{Considerações finais}

Entre traços e curvas, surge o entrecruzamento de percepções, leituras, a vida como texto e aquilo que se revela nas ilustrações também fica, ao mesmo, tempo, subentendido nas palavras: é, pois, a força da narrativa que, para Benjamin (1987), não se entrega à exaustação das explicações. Na graphic novel de Grande Sertão: veredas, o movimento e a mudança espaçotemporal se dão pela interação entre as ilustrações, os trechos literais da obra e as referências sociais e culturais que cada traço guarda consigo. Há, dessa forma, a costura de informações e o preenchimento de lacunas que, por ventura, ficaram vagos no romance.

Diante do que foi aqui discutido, pode-se dizer que o design é, assim, uma forma de vivência que tende a se tornar narrativa e criar identidades na medida em que dialoga com as referências culturais da matéria viva com a qual se relaciona. Ele é, nessa medida, uma experiência singular que talha na pessoa que projeta, observa ou consome determinado produto, impressões que podem tanto ser complementadas quanto confrontadas pelas memórias e referências de cada um. E é nesse encontro de impressões (ou desencontro, depende do caso), que ele produz conhecimento, experiência e percepção.

Essas interações entre saberes e fazeres tão vastos e vindos de tempos e espaços tão distintos se assemelham às folhas que se desprendem das veredas e movem-se pelo sertão em graphic novel no ritmo dos ventos e das brisas. Misturam-se palavras e imagens, modificam-se os tons, transformam-se em outras matérias, difundem-se no cascalho da estrada de chão ou seguem nas correntezas dos cursos d'água que compõem a travessia do espaço de Grande Sertão: veredas.

Seriam, no entanto, as mesmas folhas das mesmas veredas? Em certa medida, sim; em certa medida, não. As folhas continuam folhas, assim como as palavras continuam palavras, mas se transformam. O lugar de onde saem e os redemoinhos pelos quais passam as modificam: a dispersão constrói o discurso conforme as circunstâncias. Daí que o sertão do romance publicado em 1956 e o sertão de 2014 da obra adaptada, estão num limiar que dilui as divisões para tornar a narrativa uma construção de linguagem.

O sertão que surge por meio da ressignificação promovida pelo design é um sertão de muitos tons e assim como o movimento das folhas, vai se modificando de acordo com os lugares nos quais se insere e conforme a luz que incide. Há uma tensão que o polariza: escrita e imagem, calmaria e violência, amor e ódio... Mas há também uma questão que os mescla: no caminho do meio, nas ondas do rio, o design que concede forma às narrativas faz com que a significação de cada uma das obras seja compreendida dentro de uma prática discursiva específica. 0 tempo, o espaço e os contextos mudam. Os significados também.

Os vários fragmentos, vindos dos mais diversos vestígios, formam uma colcha de retalhos que é constantemente costura e recosturada pelas mais diferentes mãos e vozes, rastros e memórias. Essa colcha pode ser comparada aos quadrinhos contidos na graphic novel. O design, é, 
pois, uma narrativa também e, ao tecer os traços e as curvas que desenham o sertão, promove significados que detalham cada identidade ali representada.

Mas, ainda assim, os rios seguem inacabados... por enquanto, são apenas travessias em contínua experiência. Talvez, um dia, encontrem o infinito... Mas, até lá, os emaranhados simbólicos, desenhados após cada traço, no entremeio de cada curva e na entrelinha de cada palavra, podem permanecer abertos por muito tempo e são esses detalhes que fazem com que a construção do conhecimento e a história tenham tantos caminhos e sejam tão diversificados, valorizando o que se pode chamar de memória e identidade cultural.

\section{Referências}

BENJAMIM, Walter. O narrador: considerações sobre a obra de Nikolai Leskov. In: Obras escolhidas: magia e técnica, arte e política. São Paulo: Brasiliense, 1985. p. 222-232.

BOLLE, Willi. Um romance de formação do Brasil. In: Cadernos de Literatura Brasileira. Edição Especial comemorativa dos 10 anos dos Cadernos de Literatura Brasileira, no 20 e 21, p. 270-282. São Paulo: Instituto Moreira Salles, dezembro de 2006.

BONSIEPE, Gui. Identidade e contra-identidade do design. In: MORAES, Dijon; KRUCKEN, Lia (orgs). Cadernos de Estudos Avançados em Design - Design e Identidade. 2a ed. Belo Horizonte: EdUEMG, 2016. p.63-74.

FOUCAULT, Michel. Capítulos selecionados (As unidades do discurso; As formações discursivas; A formação dos objetos; A formação das modalidades enunciativas; A formação dos conceitos; $A$ formação das estratégias). In: A arqueologia do saber. Trad. Luiz Felipe Baeta Neves. 5a ed. Rio de Janeiro: Forense Universitária, 1997. p.23-85.

GAGNEBIN, Jeanne Marie. O que significa elaborar o passado? O rastro e a cicatriz: metáforas da memória (capítulos selecionados). In: Lembrar, escrever, esquecer. São Paulo: Editora 34, 2006.

MORAES, Dijon; KRUCKEN, Lia; REYES, Paulo. Design e identidade: perspectivas contemporâneas sobre a cultura material. In: MORAES, Dijon; KRUCKEN, Lia (orgs). Cadernos de Estudos Avançados em Design - Design e Identidade. 2a ed. Belo Horizonte: EdUEMG, 2016. p. 9-12.

RIBEIRO, Milton. Planejamento Visual Gráfico. 8aed. Brasília: LGE Editora, 2003.

ROSA, João Guimarães. Grande Sertão: veredas. 1a ed. Rio de Janeiro: Nova Fronteira, 2006.

ROSA, João Guimarães. Grande Sertão: veredas - adaptação da obra de João Guimarães Rosa. Graphic novel. Ilustração: Rodrigo Rosa. Roteiro: Eloar Guazzelli. 1ạ ed. São Paulo: Globo, 2014. $180 p$.

SUDJIC, Deyan. Linguagem. In: A Linguagem das Coisas. Trad. Adalgisa Campos da Silva. Rio de Janeiro: Intrínseca, 2010. p. 10-50. 